\title{
CHARACTERIZATION OF MORPHOLOGY IN HEALTHY, TRAUMATIZED AND AGED KNEE MENISCUS OF DIFFERENT SPECIES: A PILOT STUDY
}

\author{
Marija Podlesnaja ${ }^{1}$, Mara Pilmane ${ }^{2}$, Modris Ciems ${ }^{3}$ \\ ${ }^{1}$ Institute of Anatomy and Anthropology, Riga Stradiňs University, Riga, Latvia \\ ${ }^{2}$ Institute of Anatomy and Anthropology, Riga Stradinš University, Riga, Latvia \\ ${ }^{3}$ Traumatology and Orthopaedics Hospital, Riga, Latvia, LV-1005
}

\begin{abstract}
Meniscus is a fibrocartilaginous anatomical structure that realizes complicated biomechanical functions in the knee joint. However, no comparative morphology studies have been done on different species and conditions regarding the meniscus. Thus, the aim of our pilot study was to compare the morphology of traumatized and aged human and healthy deer meniscus to reveal the tissue ground, growth, degeneration, cell death and inflammation factors.

The study included surgery materials from one deer and two humans. Biotin-streptavidin immunohistochemistry was performed for detection of tissue TGF $\beta 1$, MMP2, MMP9, collagen I, caspase, Il-1, Il-6, Il-10. The results were evaluated semiquantitatively. An abundant number of Collagen I positive cells were detected in the disordered human meniscus but not in the deer one. TGF $\beta 1$ was seen in numerous to abundant number of cells in all the three cases. MMPs and caspase were distributed with numerous to abundant cells in both human and deer meniscus. Numerous to abundant cells of traumatized and aged human menisci showed IL-1 and IL-6, while the deer meniscus demonstrated cytokine expression in a moderate number of cells only in limited zones. The traumatized human meniscus possessed an abundant number of IL-10 positive cells, while the deer and the aged human meniscus showed mainly a moderate number of IL-10 cells with some elevation of cytokine in superficial and deepest layers of the meniscus.
\end{abstract}

Keywords: Meniscus; human; deer; morphology; degenerative; healthy 


\section{INTRODUCTION}

The meniscus is an important fibrocartilagineus anatomical structure that is crescent-shaped and is situated in the joint cavity of the human knee. They are also represented in such joints as wrist, acromioclavicular, sternoclavicular and temporomandibular joints in humans [18]. In different animals, the location of the meniscus can differ [25].

The importance of menisci's role in complex biomechanical processes is well shown in the correlation between meniscal tears, partial or total meniscectomy, meniscal degeneration cases and progression of human knee osteoarthritis [23]. As the main function of the meniscus is dispersal of body weight during movement and reduction of frictions, the cellular structure of the meniscus is very specific [9]. The meniscus is defined as a fibrocartilage because of the form of the major part of its cells, which are rounded or oval-shaped, and the extracellular matrix that has a partly fibrous appearance when viewed through the light microscope [3].

There is a classification of meniscus cells that was offered by Ghadially et al. (1983) and is based on their shape and the absence or presence of a territorial matrix [10]. All cells that are present in the meniscus are divided into chondrocytes, fibroblasts and cells of intermediate morphology. Type I collagen has been found to be the most common fibrillar collagen in meniscus tissue, as distinct from articular cartilages where the major part of fibrillar collagen is type II collagen [8]. This is an important parameter that can be used as a criterion for distinguishing the fibrocartilage (type I collagen is found in the majority) and the hyaline cartilage tissue (type II collagen presented), and to differentiate meniscus cells from chondrocytes. McDevitt et al. (1986) called oval-shaped meniscal cells fibrochondrocytes because they produce type I collagen despite their chondrocyte-like morphology [15]. According to the location of the cells in the meniscus tissue towards the inner part and outer layer of the structure, three distinct cell populations could be identified: the abovementioned fibrochondrocytes that are primarily situated in the inner half of the meniscus (the forces that act in this part are predominantly compressive); the fibroblast-like cells that are located in the outer fraction of the meniscus (which is more fibrous and is connected with more tensile forces); and superficial zone cells that occupy the surface of the meniscus that in in contact with the synovial fluid [3].

It is important to compare the molecular phenotype of the healthy and normally functioning meniscus with that of the torn or degenerated meniscus. For example, TGF $\beta 1$ protein plays one of the most significant roles in meniscus 
development and functioning. The research results of Verdonk et al. (2005) on the human meniscus cell phenotype revealed that TGF $\beta 1$ molecule's presence stimulated cell proliferation and the synthesis of aggrecans and type I and type II collagens [27]. Being known as an important inductor of producing the above-mentioned molecules, TGF $\beta 1$ induces a similar increase in articular chondrocytes, intervertebral disc cells, chondroprogenitor cells and is also considered to promote a chondrogenic phenotype in meniscus cells. An increase in aggrecan synthesis rates, an aggregation of them in hyaluronan-aggrecan complexes and production of biglycans in alginate cultures has been observed in the presence of TGF $\beta 1$ [27]. TGF $\beta 1$ also plays an important role in the meniscus healing process. So, in the case of meniscal lesions in dogs, periosteum graft as a source of chondrogenic factors with a combination of TGF $\beta 1$ stimulation was used, and the tissue with an old lesion of avascular area healed completely in 16 weeks [1].

The meniscus also widely expresses matrix metalloproteinases (calciumdependent zinc-containing endopeptidases), which are enzymes that degrade the extracellular matrix and trigger inflammation processes. The stimulation of normal meniscus cell cultures with pro-inflammatory factors (IL-1 $\beta$, IL-6 or FnF (fibronectin fragments) has led to some significant alterations [26]. The above-mentioned pro-inflammatory stimuli markedly increase the expression of matrix-degrading enzymes, including different types of MMPs. Interestingly, the specific type of expressed MMP depended on the stimuli that were used. All kinds of factors increased the expression of MMP-1, but IL- $1 \beta$ especially stimulated MMP-2 and MMP-10 expression. IL-6, in turn, stimulated MMP-3 expression [26]. These researches show the correlation between inflammatory factors (interleukins) and matrix degradation by matrix metalloproteinases. The same results can be found in the research of Brophy et al. (2012) who wrote about molecular analysis of age- and sex-related gene expression in meniscal tears. The authors mention that the level of MMP-1, MMP-9 and IL-1 $\beta$ was significantly higher in patients with meniscal tears, who were under the age of forty years than it was in those over the age of forty years [5].

Programmed cell death is an important mechanism that forms a part in cell life. Caspases family is one of the most widespread families of proteases enzymes (their specificity is explained with cysteine protease activity). Robertson et al. (2006) researched pro-apoptotic and matrix-degradative gene expression following the induction of osteoarthritis in rabbits. Caspase 8 and Fas ligand significantly increased in mature animals' menisci and cartilages with induced osteoarthritis, compared with control animals [21]. Haywood 
and Yammani (2016) researched palmitate influence on apoptosis promoting in meniscus cells. They wrote that palmitate treatment increased the expression of caspase-3, in this way promoting apoptosis in meniscus cells [11].

An inflammation process that is directly connected to traumatic lesions or degeneration processes in tissues, can appear in torn menisci or in meniscal tissues of aged people. There is a multitude of inflammation factors, proteinases and signal molecules that take part in this complicated mechanism. From all, interleukins are the most widespread ones. No inflammations of meniscus in human body can occur without interleukins. Hennerbichler et al. (2007) researched IL-1 and TNF- $\alpha$ inhibitive effect on the porcine meniscus in vitro and concluded that meniscal lesions in some untreated samples showed a severe capacity for intrinsic repair, including increase in cell accumulation and repair strength during the experiment, but no repair was noticed in the presence of IL-1 or TNF- $\alpha$ [12]. Other researchers have written about IL-10 ameliorative effect on TNF- $\alpha$ induced meniscus degeneration in mature meniscal tissue [4]. IL-10, which can prevent the mechanism of meniscal degeneration induced by TNF- $\alpha$, is considered to be the key cytokine of osteoarthritis. IL-10 administration might improve the biological regeneration of meniscal tissue and might become an approach in degenerative meniscus injuries and post-traumatic sport injuries treatment [4]. The level of synovial fluid biomarkers in patients with knee osteoarthritis (OA) and meniscus injury (MI) was studied by Ding et al. (2017). The results showed the synovial fluid levels of vascular endothelial growth factor (VEGF) and IL-6 to be severely higher in patients with OA, while IL-10 was lower in patients with OA, compared to MI patients [7].

Our aim was to compare the morphology of traumatized and aged human and healthy deer meniscus to reveal the tissue basic and growth, degeneration, cell death and inflammation factors.

\section{MATERIALS AND METHODS}

The study included three surgery materials from deer (Cervus elaphus) and two human patients (Homo sapiens sapiens). The tissues were taken from knee joints' menisci during meniscectomy procedure and are the property of the collection of the Institute of Anatomy and Anthropology at RSU.

The tissues were fixed for a day in a mixture of $2 \%$ formaldehyde and 0.2 picric acid in $0.1 \mathrm{M}$ phosphate buffer ( $\mathrm{pH}$ 7.2). Afterwards, they were rinsed in thyroid buffer containing $10 \%$ saccharose for 12 hours and then embedded into 
paraffin. Three-micrometre-thin sections were cut, which were then stained with hematoxylin and eosin (H\&E) for morphological evaluation. The biotinstreptavidin biochemical method (Guesdon et al., 1979) was used for immunohistochemistry (IMH) to detect: TGF $\beta 1$ (orb7087, 1:100, Biorbyt, UK), MMP2 (orb11061, 1:200, Biorbyt, UK), MMP9 (orb11064, 1:100, Biorbyt, UK), type I collagen (ab88147, 1:100, Abcam, UK), caspase (sc-81653, 1:100, Santa CRUZ BIOTECHNOLOGY INC., USA), Il-1 (orb308737, 1:100, Biorbyt, UK), Il-6 (sc-130326, 1:100, Santa CRUZ BIOTECHNOLOGY INC., USA), Il-10 (250713, 1:100, BioSite, Sweden). The slides were analysed by light microscopy. The results were evaluated by grading the appearance of positively stained cells in the visual field (Pilmane et al., 1998). No positive structures in the visual field were labelled as 0 , rare positive structures were labelled with $0 /+$, few positive structures: + , few to moderate number of positive structures in the visual field: $+/++$, moderate number of positive structures in the visual field: ++ , moderate to numerous positive structures in the visual field: $++/+++$, numerous positive cells in the visual field: +++ , numerous to abundant structures in the visual field: $+++/++++$ and abundance of positive structures in the visual field was labelled as ++++ .

\section{RESULTS}

Routine evaluation showed meniscus cells surrounded by a large amount of extracellular matrix. Cells were most densely located in the outer part of the deer meniscus (Fig. 1). Deer meniscus structure was homogenous enough, there were no tears, its border was flat (Fig. 1). Cells were more evenly distributed in the human meniscus (Fig. 2). Many tears and an uneven border were observed in the traumatized human meniscus (Fig. 2). There were highly vascularized areas in the inner part of the aged human meniscus (Fig. 3).

Type I collagen was found in all cell types of three different menisci. Its presence ranged from few to moderate $(+/++)$ in the healthy deer meniscus (Fig. 4) to abundant $(++++)$ in the traumatized and aged human meniscus (Fig. 5) (see Table 1). 
Table 1. Distribution and appearance of different tissue factors in menisci of different species.

\begin{tabular}{|c|c|c|c|c|c|c|c|c|c|}
\hline \multirow{2}{*}{$\begin{array}{l}\text { Subject } \\
\text { Factors }\end{array}$} & \multicolumn{3}{|c|}{ Deer meniscus } & \multicolumn{3}{|c|}{ Traumatized meniscus } & \multicolumn{3}{|c|}{ Aged meniscus } \\
\hline & 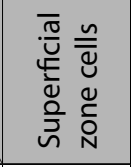 & 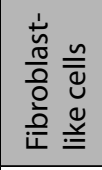 & 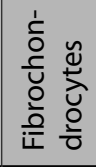 & 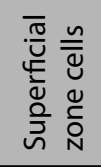 & 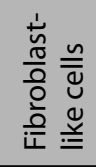 & 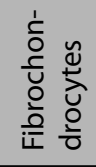 & 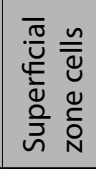 & 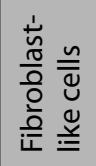 & 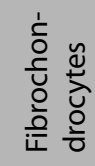 \\
\hline TGF $\beta 1$ & ++++ & +++ & + & & & ++++ & & ++++ & \\
\hline MMP2 & ++++ & ++++ & 0 & & & ++++ & & & +++ \\
\hline MMP9 & ++++ & ++++ & 0 & & & ++++ & & ++++ & ++++ \\
\hline Caspase & ++++ & ++ & 0 & & & $\begin{array}{l}+++/ \\
++++\end{array}$ & & & $\begin{array}{l}+++/ \\
++++\end{array}$ \\
\hline $\begin{array}{l}\text { Collagen } \\
\mathrm{I}\end{array}$ & $+/++$ & $+/++$ & $+/++$ & ++++ & ++++ & ++++ & ++++ & ++++ & ++++ \\
\hline IL-1 & ++ & 0 & ++ & +++ & +++ & +++ & ++++ & ++++ & ++++ \\
\hline IL-6 & $++/+++$ & 0 & 0 & ++++ & ++++ & ++++ & $\begin{array}{l}+++/ \\
++++\end{array}$ & $\begin{array}{l}+++/ \\
++++\end{array}$ & $\begin{array}{l}+++/ \\
++++\end{array}$ \\
\hline IL-10 & ++ & ++ & +++ & ++++ & ++++ & ++++ & ++++ & ++ & ++ \\
\hline
\end{tabular}

TGF $\beta 1$ protein was also widely expressed in all meniscal materials, but the number of positive cells varied. In the healthy deer meniscus, TGF $\beta 1$ positive cells were abundant $(++++)$ in the superficial zone and ranged from numerous $(+++)$ to few $(+)$ in the inner part of the meniscus (Fig. 6). In the traumatized human meniscus, an abundant $(++++)$ number of TGF $\beta 1$ positive fibrochondrocytes was detected, but in the aged human meniscus - an abundant $(++++)$ number of TGF $\beta 1$ positive fibroblast-like cells (Fig. 7).

An abundant (++++) number of both MMP2 and MMP9 positive superficial zone cells and fibroblast-like cells was found in the deer meniscus, while its fibrochondrocytes were seen to be without positive enzyme activity (Fig. 8). The human traumatized and aged meniscus had a numerous to abundant (++++) number of both MMP2 and MMP9 positive fibrochondrocytes (Fig. 9-10). There was an abundant (++++) number of MMP9 positive fibroblastlike cells in the aged meniscus.

There was a moderate $(++)$ (in the inner zone) to abundant $(++++)$ (in the superficial zone) number of caspase positive cells in the deer meniscus (Fig. 11). Caspase positive fibrochondrocytes were found in the traumatized and aged human meniscus, and their number ranged from numerous $(+++)$ to abundant (++++) (Fig. 12-13). 
The number of IL-1, IL- 6 and IL-10 positive cells in the deer meniscus ranged from moderate (++) to numerous $(+++)$ (Fig. 14). Only superficial zone cells were IL- 1 and IL- 6 positive, while all deer meniscus cells were IL-10 positive (Fig. 15). All cell types of traumatized and aged human menisci were IL-1, IL-6 and IL-10 positive and their number ranged from numerous $(+++)$ to abundant (++++) (Fig. 16). An exception was the moderate (++) number of IL-10 positive fibroblast-like cells and fibrochondrocytes of the aged meniscus.

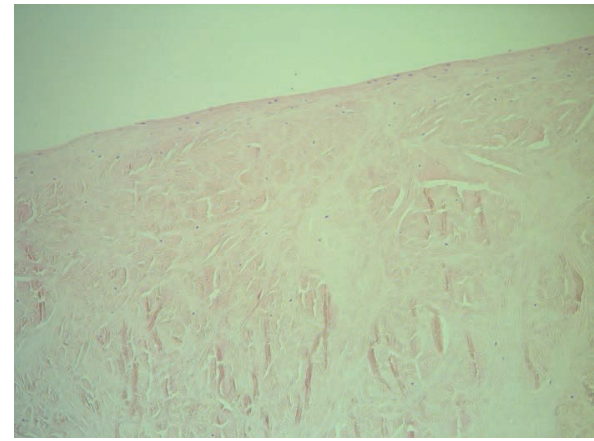

Figure 1. Deer meniscus with homogenous structure, flat border and cells, densely distributed in the outer layer. $\mathrm{H} \& \mathrm{E}, \mathrm{X} 100$

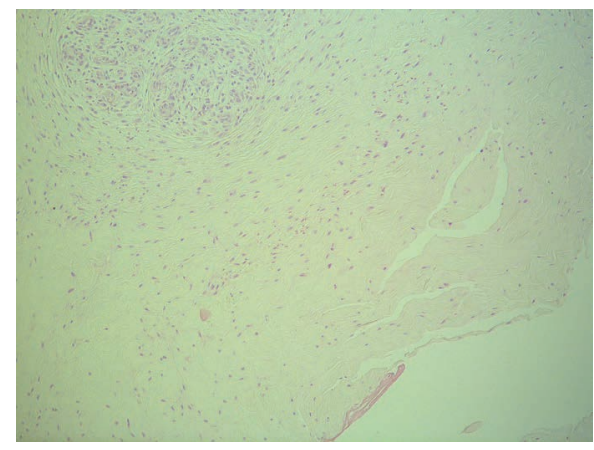

Figure 3. Aged human meniscus. Note wellvascularized area in the upper-left corner. $\mathrm{H} \& \mathrm{E}, \mathrm{X} 100$

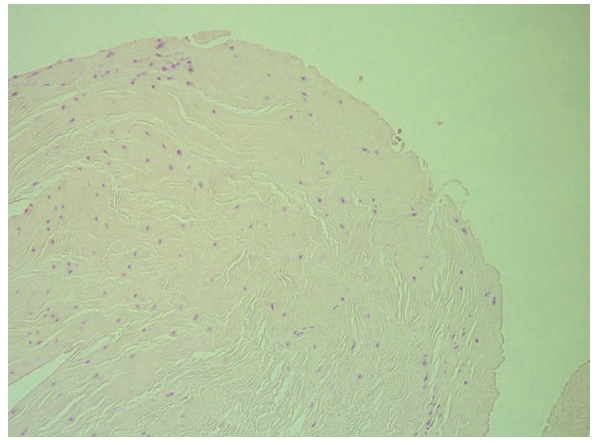

Figure 2. Traumatized human meniscus. Note tears, uneven border and evenly distributed cells. H\&E, X100

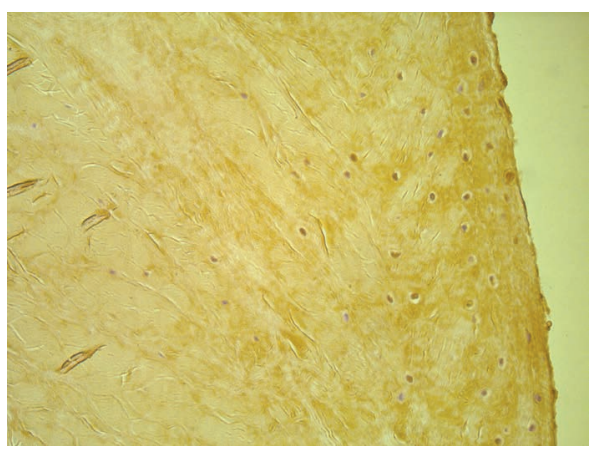

Figure 4. Few to moderate number of collagen I positive structures in deer meniscus. Collagen I IMH, X250 


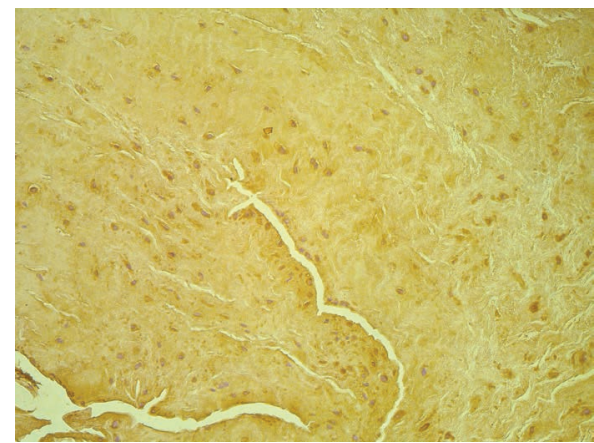

Figure 5. Abundant number of collagen I positive structures in traumatized human meniscus. Collagen I IMH, X200

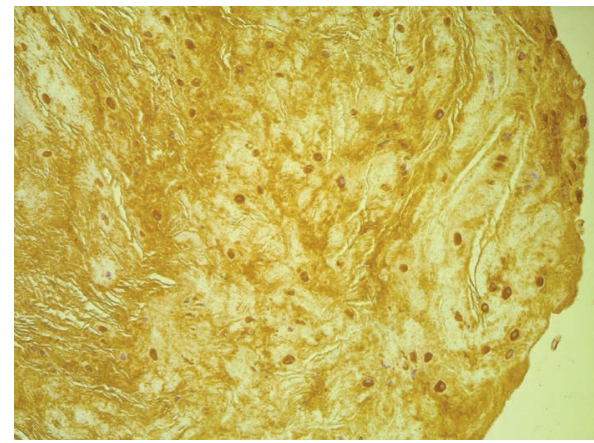

Figure 7. Abundant number of TGF $\beta 1$ positive fibrochondrocytes in traumatized human meniscus. TGF $\beta 1 \mathrm{IMH}, \mathrm{X} 200$

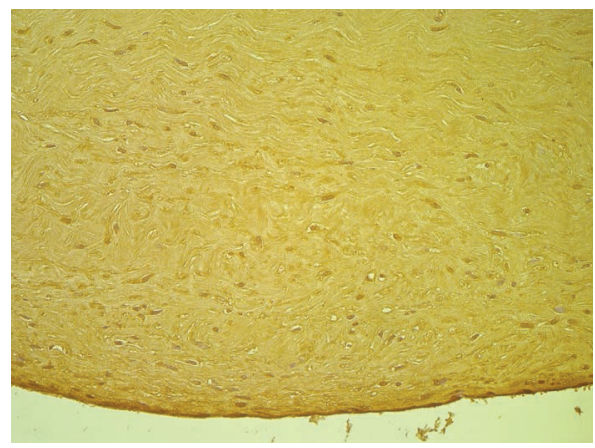

Figure 9. Numerous number of MMP2 positive fibrochondrocytes in aged human meniscus, MMP2 IMH, X200

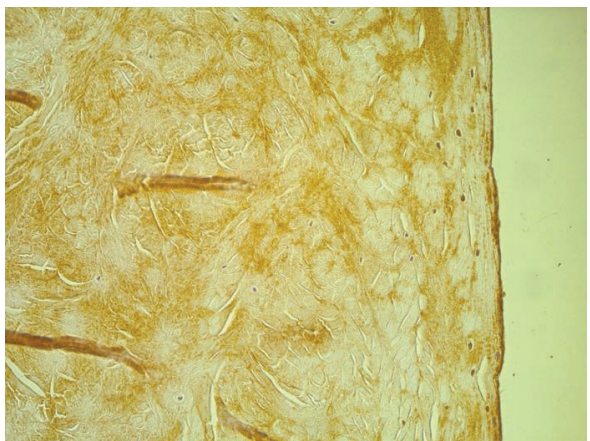

Figure 6. Abundant (in superficial zone) to few (in the inner zone) number of TGF $\beta 1$ positive cells in deer meniscus. TGF $\beta 1 \mathrm{IMH}, \mathrm{X} 200$

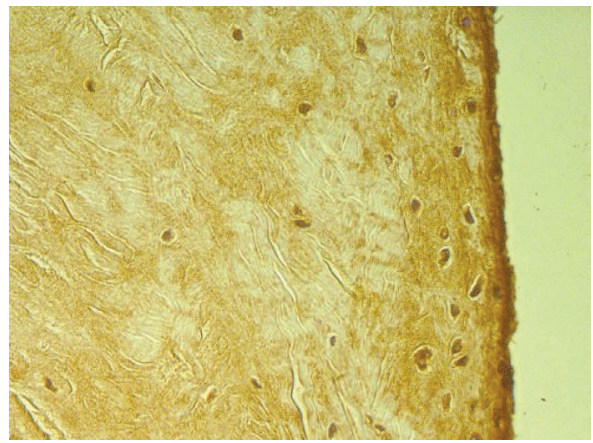

Figure 8. Abundant number of MMP2 positive structures in deer meniscus. MMP2 IMH, X200

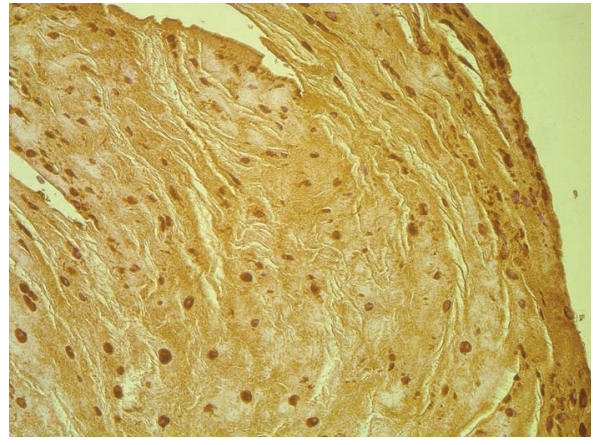

Figure 10. Abundant number of MMP9 positive fibrochondrocytes in traumatized human meniscus. MMP9 IMH, X200 


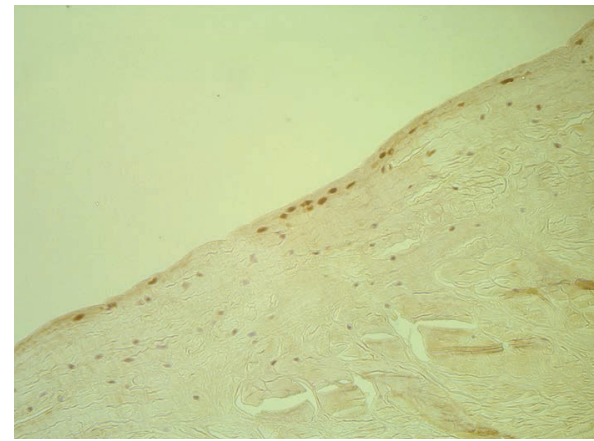

Figure 11. Moderate number of caspase positive fibroblast-like cells and abundant number of caspase positive superficial zone cells in deer meniscus. Caspase IMH, X200

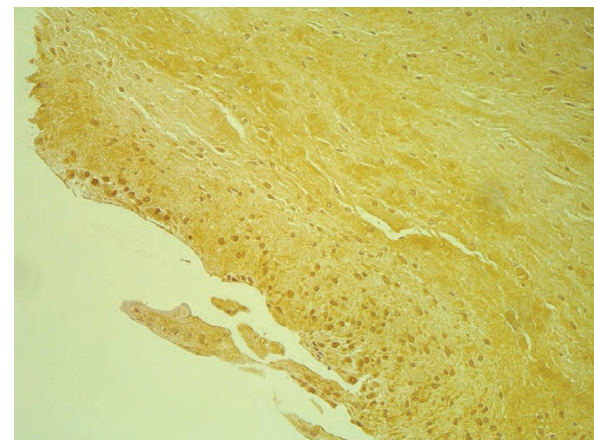

Figure 13. Abundant number of caspase positive fibrochondrocytes in aged human meniscus. Caspase IMH, X200

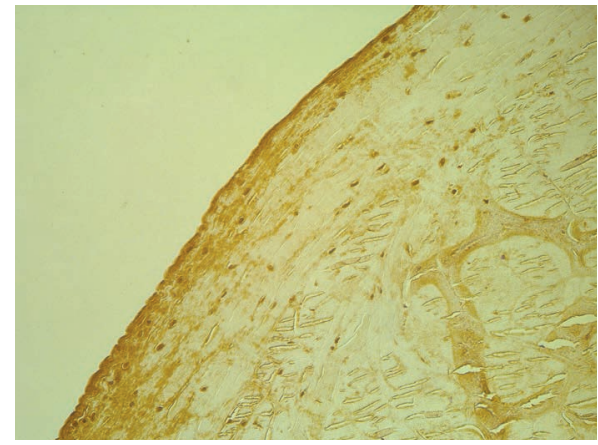

Figure 15. Moderate to numerous number of IL-10 positive cells of deer meniscus. IL-10 $\mathrm{IMH}, \mathrm{X} 200$

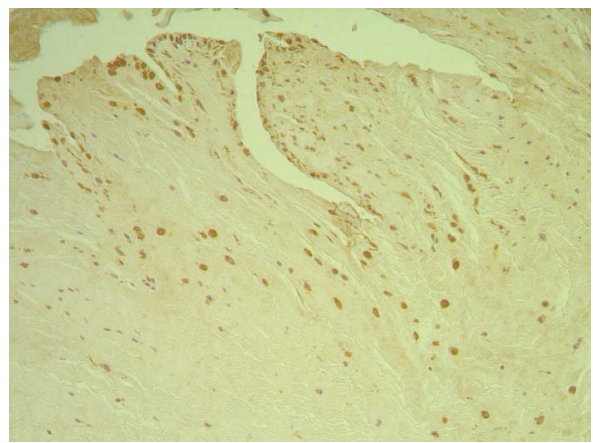

Figure 12. Abundant number of caspase positive fibrochondrocytes in traumatized human meniscus. Caspase IMH, X100

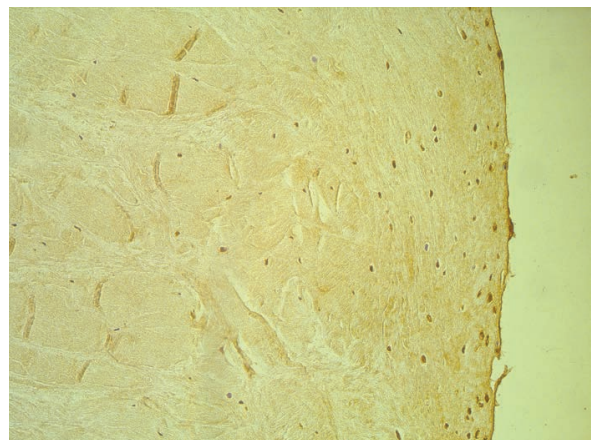

Figure 14. Moderate to numerous number of IL- 6 positive superficial zone cells of deer meniscus. IL-6 IMH, X200

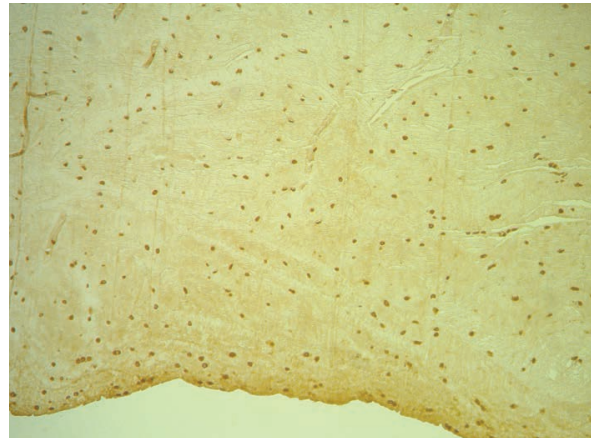

Figure 16. Abundant number of IL- 6 positive cells of traumatized human meniscus. IL-6 IMH, X100 


\section{DISCUSSION}

Type I collagen is the most common fibrillar collagen in meniscus tissue as well as in bone tissue, making them stiffer and more resistant to mechanical stress [28]. In our study, limited expression of collagen I was detected in the healthy deer meniscus in comparison with the disordered human meniscus. The reduced production of collagen I in the deer meniscus could be explained with the wild life of the animal, which includes both mechanical pressure during displacements and nutrition specificities during the year. The collagen molecule has a specific amino acid composition - its main components are glycine, proline and lysine [17]. The main sources of these amino acids are meat, fish, and dairy products, and they usually have no place in wild hoofed ruminants' diet. On the contrary, humans, having a balanced diet, provide themselves with amino acids in necessary amounts. Vitamin C is a cofactor for hydroxylation of lysine and proline, and the successful process of type I collagen synthesis in the deer organism can be explained with the particular role of lichen, which is rich in ascorbic acid, in their diet [20]. Another explanation for the relatively limited type I collagen expression in the deer meniscus can lay in the high level of the stress-hormone cortisol in wild animal blood, compared to comfortably living humans [2]. Cortisol stimulates the degradation of collagen into amino acids [13]. Cortisol also decreases both collagen synthesis and enzymes hydroxylases activity, as it was indicated in Oikarinen's research (1977) on cortisol effect on collagen biosynthesis in chick-embryo tendon cells [16]. The abundant number of type I collagen positive cells in disordered human menisci can be explained with compensatory processes that take place in the tissues that are vulnerable to heavy compression. A confirmation for this assumption was found in Paavo Komi's book Strength and Power in Sport, in which the author describes some experiments on chondrocytes obtained from fibrocartilage and enhanced synthesis of collagen and proteoglycans caused by cyclic compression [14].

A correct balance in cytokine expression was found in the deer meniscus with the predominance of anti-inflammatory interleukin-10. Interestingly, the moderate to numerous numbers of fibrochondrocytes and fibroblast-like cells of the deer meniscus were IL-10 positive and less positive for IL-1, compared to superficial zone cells. We explain the most numerous number of IL-10 positive fibrochondrocytes, which are situated in the inner part of the meniscus, with the highest level of biomechanical stress this zone is vulnerable to. Crowder et al. (2016) in their research on material cues as potent regulators of epigenetics and stem cell function wrote that biophysical signals could modulate the 
epigenetic status of cells [6]. That is why the region with massive biomechanical pressure can normally regulate inflammation processes with high level of antiinflammatory cytokines. At the same time, moderate to numerous numbers of IL-1 and IL-6 positive superficial zone cells found in the deer meniscus correlate with the smaller number of IL-10 positive superficial zone cells. The cells of this zone are in contact with the synovial fluid, and, possibly, the inflammation process in the superficial zone can be explained with the impact of interleukins on the synovial fluid. Wild life, nutrition disadvantages, infections and high level of physical activity can trigger different inflammation processes in animals' organisms, which explains cytokine presence in the synovial fluid. For example, IL- 6 gene expression can be induced by INF- $\gamma$ and TNF- $\alpha$ [22].

In our study, rich cytokine expression was observed in the aged human meniscus with pro-inflammatory cytokine secretion predominance. The decrease in IL-10 positive fibroblast-like cells and fibrochondrocytes (moderate number) can be explained with age-related changes in the human organism. Ye and Johnson (2001) indicated that age is associated with increased inflammation and elevation of pro-inflammatory cytokines, as IL-1, IL-6, level, and - on the contrary - decreasing the anti-inflammatory cytokine (IL-4, IL-10) level [29]. The high level of pro-inflammatory cytokines expression results from the decreased IL-10 expression. As Behrendt et al. (2017) wrote, IL-10 ameliorates pro-inflammatory cytokines induced meniscus degeneration; so, its presence reduction in tissue can cause inflammation development [4]. Ding (2017) discovered in the research on synovial fluid biomarkers that patients with knee osteoarthritis had a lower IL-10 expression level in their meniscus cells in comparison to patients with meniscal injury. Interestingly, the latter had a lower level of IL-1 and IL- 6 expression than the former [7]. The research by Spencer (1996) also noted the possible linkage of dysregulation of IL-10 production with aging to the age-associated decline in DHEAS (dehydroepiandrosterone sulphate) [24]. He underlined the ability of DHEAS treatment to restore normal control over IL-10 expression. A decline in DHEA could explain the decrease of IL-10 expression in aged meniscus cells. Our study showed that IL-10 expression in other injured meniscus cells was very high, compared to the degenerative meniscus; so, the patients' age and their DHEAS level could be a crucial point in this difference.

There can be a connection between IL-10 expression intensity and type I collagen expression in the deer meniscus. As it was written above, few to a moderate number of collagen I positive fibroblast-like cells and fibrochondrocytes were found in the deer menisci, while the number of IL-10 positive cells 
was moderate to numerous. Reitamo (1994) described that tissue incubation with IL-10 resulted in a reduction in immunostaining of cell cultures with antibodies to human type I collagen, while IL-10 affected the expression of several genes involved in collagenase synthesis [19]. That means that IL-10 could play a significant role in the breakdown and remodelling of the extracellular matrix.

To sum up, the deer meniscus demonstrated the highest approximation to the healthy meniscal structure and normal molecular phenotype despite the deer's wild lifestyle, possible infections and nutritional weaknesses. Traumatized and aged human menisci showed rich interleukin expression, while the degenerative process in the latter could be explained by the imbalance in proand anti-inflammatory cytokine expression.

\section{CONCLUSIONS}

The deer meniscus with relatively limited collagen I expression probably proved the limitation in hard tissue metabolism due to the wild life but might also serve as a key comparative point for detection of compensatory increase of protein in the human traumatized and aged meniscus. The disordered human menisci were characterized by rich pro- and anti-inflammatory cytokine expression with some signs of decompensation in IL-10 appearance during aging, while the deer meniscus showed correct balance in cytokine expression (with less pro-, but more anti-inflammatory cytokine secretion in meniscus).

\section{ABBREVIATIONS:}

TGF $\beta 1$ - transforming growth factor beta 1

MMP - matrix metalloproteinase

IL - interleukin

\section{REFERENCES}

1. Albornoz de P.M., Forriol F. (2012). The meniscal healing process. Muscles, Ligaments and Tendons Journal, 2, 10-18.

2. Bayazit V. (2009). Evaluation of Cortisol and Stress in Captive Animals. Australian Journal of Basic and Applied Sciences, 3, 2, 1022-1031.

3. Beaufils Ph., Verdonk R. (2010). The Meniscus. Berlin, Heidelberg: SpringerVerlag. 407, 20-31.

4. Behrendt P., Häfelein K., Preusse-Prange A., Bayer A., Seekamp A., Kurz B. (2017). L-10 ameliorates TNF- $\alpha$ induced meniscus degeneration in mature 
meniscal tissue in vitro. BMC Musculoskeletal Disorders, 18, 197. https://doi. org/10.1186/s12891-017-1561-X

5. Brophy R.H., Rai M.F., Zhang Z., Torgomyan A., Sandell L.J. (2012). Molecular analysis of age and sex-related gene expression in meniscal tears with and without a concomitant anterior cruciate ligament tear. J Bone Joint Surg Am, 94, 5, 385-393. https://doi.org/10.2106/JBJS.K.00919

6. Crowder S.W., Leonardo V., Whittaker Th., Stevens M.M. (2016). Material Cues as Potent Regulators of Epigenetics and Stem Cell Function. Cell Stem Cell, 18, 1, 39-52. https://doi.org/10.1016/j.stem.2015.12.012

7. Ding J., Niu X., Su Y., Xiaolin L. (2017). Expression of synovial fluid biomarkers in patients with knee osteoarthritis and meniscus injury. Experimental and Therapeutic Medicine, 14, 2, 1609-1613. https://doi.org/10.3892/etm.2017.4636

8. Eyre D.R., Muir H. (1976). Types I and II collagens in intervertebral disc. Interchanging radial distributions in annulus fibrosus. Biochemical Journal, 157, 1, 267-270. https://doi.org/10.1042/bj1570267

9. Fox A.J., Asheesh B., Scott A.R. (2012). The Basic Science of Human Knee Menisci: Structure, Composition, and Function. Sports Health, 4, 4, 340-351. https://doi.org/10.1177/1941738111429419

10. Ghadially F.N., Lalonde J.M., Wedge J.H.J. (1983). Ultrastructure of normal and torn menisci of the human knee joint. Journal of Anatomy, 136, Pt 4, 773-91.

11. Haywood J., Yammani R.R. (2016). Free fatty acid palmitate activates unfolded protein response pathway and promotes apoptosis in meniscus cells. Osteoarthritis and Cartilage, 24, 5, 942-5. https://doi.org/10.1016/j.joca.2015.11.020

12. Hennerbichler A., Moutos F.T., Hennerbichler D., Weinberg J.B., Guilak F. Ph.D. (2007). Interleukin-1 and tumor necrosis factor alpha inhibit repair of the porcine meniscus in vitro. Osteoarthritis and Cartilage, 15, 9, 1053-1060. https://doi.org/10.1016/j.joca.2007.03.003

13. Houck, J.C.; Sharma V.K., Patel Y.M., Gladner, J.A. (1968). Induction of Collagenolytic and Proteolytic Activities by Anti-Inflammatory Drugs in the Skin and Fibroblasts. Biochemical Pharmacology, 17, 10, 2081-2090. https://doi.org/10.1016/0006-2952(68)90182-2

14. Komi P.V. (2003). Strength and Power in Sport. International Olympic Committee. Blackwell Science Ltd, a Blackwell Publishing Company. 2nd edition. 108.

15. McDevitt C.A., Adams M.E., Ho A., Muir H. (1986). Isolation and characterization of high-buoyant-density proteoglycans from semilunar menisci. Journal of Bone and Joint Surgery, 68, 1, 55-64. https://doi.org/10.2106/00004623-198668010-00007

16. Oikarinen A., (1977). Effect of cortisol acetate on collagen biosynthesis and on the activities of prolyl hydroxylase, lysyl hydroxylase, collagen galactosyltransferase and collagen glucosyltransferase in chick-embryo tendon cells. Biochemical Journal, 164, 3, 533-9. https://doi.org/10.1042/bj1640533 
17. Peterkofsky B. (1991). Ascorbate requirement for hydroxylation and secretion of procollagen: Relationship to inhibition of collagen synthesis in scurvy. American Journal of Clinical Nutrition, 54 (6 Suppl), 1135S-1140S. https://doi.org/10.1093/ajcn/54.6.1135s

18. Platzer W. (2004). Color Atlas and Textbook of Human Anatomy: Locomotor system. Stuttgart: Thieme Medical Publishers.

19. Reitamo S., Remitz A, Tamai K, Uitto J. (1994). Interleukin-10 modulates type I collagen and matrix metalloprotease gene expression in cultured human skin fibroblasts. Journal of Clinical Investigation, 94, 6, 2489-92. https://doi.org/10.1172/JCI117618

20. Richardson D.H.S., Young C.M. (1977). Lichens and Vertebrates. Lichen Ecology. Academic Press, London. 550.

21. Robertson C.M., Pennock A.T., Harwood F.L., Pomerleau A.C., Allen R.T., Amiel D. (2006). Characterization of pro-apoptotic and matrix-degradative gene expression following induction of osteoarthritis in mature and aged rabbits. Osteoarthritis and Cartilage, 14, 5, 147-6. https://doi.org/10.1016/j.joca.2005.11.010

22. Sancéau J., Kaisho T., Hirano T., Wietzerbin J. (1995). Triggering of the Human Interleukin- 6 Gene by Interferon- $\gamma$ and Tumor Necrosis Factor- $\alpha$ in Monocytic Cells Involves Cooperation between Interferon Regulatory Factor-1, NFKB, and Sp1 Transcription Factors. Journal of Biological Chemistry, 270, 46, 27920-31. https://doi.org/10.1074/jbc.270.46.27920

23. Sharma L, Eckstein F, Song J, et al. (2008). The relationship of meniscal damage, meniscal extrusion, malalignment, and joint laxity to subsequent cartilage loss in osteoarthritic knees. Arthritis \& Rheumatology, 58, 1716-1726. https://doi.org/10.1002/art.23462

24. Spencer N.F., Norton S.D., Harrison L.L., Daynes R.A., (1996). Dysregulation of IL-10 production with aging: possible linkage to the age-associated decline in DHEA and its sulfated derivative. Experimental Gerontology, 31, 3, 393-408. https://doi.org/10.1016/0531-5565(95)02033-0

25. Steadman J.R., Matheny L.M., Singleton S.B. (2015). Meniscus suture repair: Minimum 10-year outcomes in patients younger than 40 years compared with patients 40 and older. American Journal of Sports Medicine, 43, 2222-2227. https://doi.org/10.1177/0363546515591260

26. Stone A.V., Loeser R.F., Vanderman K.S., Long D.L., Clark S.C., Ferguson C.M. (2014). Pro-inflammatory stimulation of meniscus cells increases production of matrix metalloproteinases and additional catabolic factors involved in osteoarthritis pathogenesis. Osteoarthritis and Cartilage, 22, 2, 264-74. https://doi.org/10.1016/j.joca.2013.11.002 
27. Verdonk P., Forsyth R., Wang J., Almqvist K., Verdonk R. (2005). Characterization of human knee meniscus cell phenotype. Osteoarthritis and Cartilage, 13, 7, 548-560. https://doi.org/10.1016/j.joca.2005.01.010

28. Viguet-Carrin S., Garnero P., Delmas P.D. (2005). The role of collagen in bone strength. Osteoporosis International, 17, 3, 319-36. https://doi.org/10.1007/s00198-005-2035-9

29. Ye S.M., Johnson R.W. (1999). Increased interleukin-6 expression by microglia from brain of aged mice. Journal of Neuroimmunology, 93, 1-2, 139-48. https://doi.org/10.1016/S0165-5728(98)00217-3

\section{Address for correspondence:}

Marija Podlesnaja

Lokomotīves iela, 78-9

Rīga, Latvia, LV-1057

$+37129363674$

E-mail: maryturm@gmail.com 